\title{
COMPARATIVE ANALYSIS OF TYPE 1 AND TYPE 2 CASSAVA PEELING MACHINES
}

\author{
C. Nathan ${ }^{1, *}$ and U. J. Udosen ${ }^{2}$ \\ 1 Department of Mechanical Engineering Federal Polytechnic Mubi, AdamaWa State, NiGERIA \\ 2 Department of Production Engineering University of Benin, Benin City, Edo STATE, NiGERIA
}

E-mail addresses: ${ }^{1}$ chindapin@gmail.com, ${ }^{2}$ udosenroyal@gmail.com

\begin{abstract}
A comparative analysis of type 1 and type 2 cassava peeling machines with nail lengths of 26mm and 20mm were investigated in order to improve peeling techniques of cassava tubers. The machines were evaluated at four (4) different speeds; (80rev/min, 90rev/min, 100rev/min, and 110rev/min), with $750 H P$ petrol engine. Cassava tubers were graded into average weights of $0.81 \mathrm{~kg}, 0.72 \mathrm{~kg}, 0.64 \mathrm{~kg}, 0.55 \mathrm{~kg}, 0.50 \mathrm{~kg}$. The results of the properties evaluated for type1 and type 2 peelers are: Weight of peeled cassava (85\% and 78\%) at 80rev/min respectively, Weight of cassava peels (16\% and $15.66 \%)$ at $80 \mathrm{rev} / \mathrm{min}$ respectively, Weight of cassava flesh loss (0.7\% and 3.26\%) at $80 \mathrm{rev} / \mathrm{min}$ respectively, weight of unpeeled cassava (0.7\% and 3.26\%) at 80rev/min respectively, Peeling efficiency (88\% and $82 \%$ ) at $80 \mathrm{rev} / \mathrm{min}$ respectively, Mechanical damage $(0.0084 \mathrm{~kg}$ and $0.040 \mathrm{~kg})$ at $80 \mathrm{rev} / \mathrm{min}$ respectively, Throughput capacity $(1041 \mathrm{~kg} / \mathrm{h}$ and $1149 \mathrm{~kg} / \mathrm{h}$ ) at 110 rev/min respectively, The results of the properties evaluated for type 1 peeler were better than type 2 peeler.
\end{abstract}

Key words: Nails, Weight, Cassava, Peelers, Flesh loss.

\section{INTRODUCTION}

\subsection{History of Cassava and Cassava Processing}

Cassava manihot esculenta, with common Names cassava, Brazillian arrowroot, manioc and tapioca [1] is a woody shrub of the euphorbiaceae (spurge) family, commonly found in South America. It is extensively cultivated as an annual crop in tropical and subtropical regions for its edible starchy tuberous root, which is a major source of carbohydrates, though it is sometimes called yucca in Spanish [2]. Cassava is the third source of food carbohydrates in the tropics, after rice and maize "cassava" [3]. Cassava is a major staple food in developing world, providing a basic diet for over half a billion people [4], it is one of the most drought tolerant crops, capable of growing on marginal soils. Nigeria is the world's largest producer of cassava followed by Brazil [5]. Cassava is classified as sweet or bitter (manihot utilissimaor manihot palmate) respectively [6]. Farmers often prefer the bitter varieties because they deter pests, animals and thieves [7]. Like other tubers and roots both bitter and sweet varieties of cassava contain ant nutritional factors and toxins [8]. It must be properly prepared before consumption. Improper preparation of cassava can leave enough residual cyanide which may result in acute partial paralysis [8]. Cassava peeling has been practiced as far back as when cassava came into existence, but the instrument for peeling has evolved from stone and wooden flint into simple house hold knife. This makes peeling of a large quantity of cassava drudgery [9]. The processing of cassava tuber for industrial or human use involves different operations of which peelings affects the quality of the resultant product especially as regards to unwanted contents. In some cases, especially when the cassava is being used for animal feed peeling may be unnecessary $[10,11]$. According to [12] the cassava peel (peelings) has two layers. The outer layer called periderm and the inner layer called cortex. The problems encountered in peeling cassava root tubers arise from the fact that cassava roots exhibit appreciable differences in weight, size, and shape [13]. There are also differences in the properties of cassava peel which vary in thickness, texture and strength of adhesion to the root flesh. Thus it is difficult to design a cassava peeling machine that is capable of efficiently peeling all roots due to wide, differences in properties of roots from various sources $[14,15]$. Several attempts have been made at solving these problems which resulted in the development of various types of cassava peeling machines [16 - 18]. However the common problem with these machines is the fact that tubers are reduced to a uniform cylindrical shape with considerable wastage of useful flesh before satisfactory peeling could be achieved [19] reported a peeling efficiency as low as $45 \%$. This research has enabled 
cassava processing to be less labor intensive and the quality of processing to be high and acceptable. Lack of effective peeling machine is responsible for the long time spent on processing cassava. Literature survey and tour of research institutions in Nigeria revealed the near absence of an effective cassava peeling machine. Peeling of cassava is therefore carried out manually by women and children. It takes about 90 hours on the average for processing $100 \mathrm{~kg}$ of garri [20] of which $65 \%$ of the time was spent on manual peeling of the cassava. The present study is aimed at the design and development of a cassava peeling machine, capable of peeling different sizes of cut to size cassava tubers incorporated with an adjustable plate, which can be used to feed different sizes of cassava to the peeling spikes (nails), thus peeling different diameter of cassava tubers.

\subsection{Peeling Methods}

\subsubsection{Manual peeling}

The manual method of cassava peeling is primitive and cumbersome; it is usually carried out by hand. In this method,a knife or sharp object is used in the removal of the cassava peels. The peeling process takes a lot of time before a good quantity of peeled cassava tuber is obtained [20].

\subsubsection{Chemical Peeling}

Chemical peeling makes use of caustic soda $(\mathrm{NaOH})$ solution to soften and loosen the skin of the cassava, but the major disadvantages of chemical peelings are [21]:

1. Cost of acquiring the caustic soda,

2. Difficulties in controlling the penetration of chemicals into the cassava tubers,

3. Difficulties in removing the trace chemicals in the cassava as it may be poisonous.

\subsubsection{Mechanical Method}

This involves mechanized means of peeling aimed at peeling a large number of cassava tubers at a time. Many mechanisms have been devised for this purpose. This includes the continuous process, the abrasive belt conveyors, and batch abrasion etc. These methods of peeling have not yielded desired results. Hence, more research is still going on in this area to bring the best way of peeling cassava [21].

\subsubsection{Steaming Method}

In this method of cassava peeling, the cassava tubers are subjected to high steam pressure over a short period of time to avoid partial cooking of the cassava. The disadvantage is that the tubers could be subjected beyond the time required, which will eventually lead to cooking of the cassava [21].

\section{MATERIALS AND METHODS}

\subsection{Materials}

The cassava (Manihot esculenta) used for the experiment was acquired from the market in Iselu Market, Benin. 50 samples of similar weight in each size range were selected and cut to a length of $200 \mathrm{~cm}$. Weighing balance was used to measure the weight of the cassava and the weight of the materials removed.

\subsection{Measuring Tools and Instruments}

Variety of tools and instruments were used to carry out different measurements on the root tubers. A tape rule was used to measure the length of cassava tubers while the diameter of the cassava tubers were measured using a pair of vernier calliper. The weight of cassava tubers before and after peeling and weight of cassava peels removed were measured with a weighing balance. The time of operation was measured using a stop watch while the residual cassava peels were removed by a knife.

\subsection{Description of the Machines (Type 1 and Type 2)}

Two different machines were used for the analysis. The type 1 cassava peeling machine having longer peeling spikes (stainless nails) of length $26 \mathrm{~mm}$ and the type 2 cassava peeling machine having shorter peeling spikes (stainless nails) of length $20 \mathrm{~mm}$. These machines were designed and fabricated at the department of production engineering, University of Benin, Benin city, Edo State, Nigeria. The peeling processes were carried out simultaneously with machines type 1 and type 2 using the same materials and method.

\subsection{Description of Type 1 Cassava Peeling Machine}

The peeling chamber and the peeling tool are mounted on a supporting frame. The peeling tool is a rotating cylindrical shaft or drum upon which peeling spikes (nails) of length $26 \mathrm{~mm}$ are permanently welded. A screw conveyor was designed and developed to pass through the peeling chamber to the chute. Both the peeling shaft and the conveyor shaft were driven by a 750HP petrol engine. A belt and pulley mechanism was used to transfer the motion from the petrol engine to the peeling shaft and to the conveyor shaft. The hopper was designed such that, cut cassava tubers placed in the machine lies horizontally on the conveyor shaft. The peeling spikes peel the cassava as the cassava passes the peeling spikes on the conveyor shaft to the outlet. The adjustable plate in the peeling chamber pushes the cassava to the peeling spikes, where a required layer of peels is removed from the cassava. The adjustable plate when adjusted allows a very little clearance between the peeling spikes and the conveyor shaft that will not allow cassava tubers to drop 
through, but large enough to allow the tuber peels to fall off and finds its way to the exit point. A guard is placed to prevent direct contact between the operator and the fast rotating peeling spikes. The pictures of the internal component of type 1 peeler, the front view of the machine and the peeling tool are shown in Figure 1, Figure 2 and Figure 5 respectively.

\subsection{Description of Type 2 Cassava Peeling Machine}

The design and development of type 2 cassava peeling machine is similar to type 1 cassava peeling machine. The difference between the two cassava peelers is the peeling spikes. Type 1 cassava peeling machine uses the longer peeling spikes (stainless nails) of length $26 \mathrm{~mm}$ and type 2 cassava peeling machine uses the shorter stainless nails of length $20 \mathrm{~mm}$. Their mode of operation is the same. And all the materials used for type 1 are equally used for type 2 cassava peeling machine. The picture of the internal component of type 2 cassava peeling machine, the front view, and the picture of the peeling spikes are shown in Figure 3, Figure4 and Figure 6 respectively.
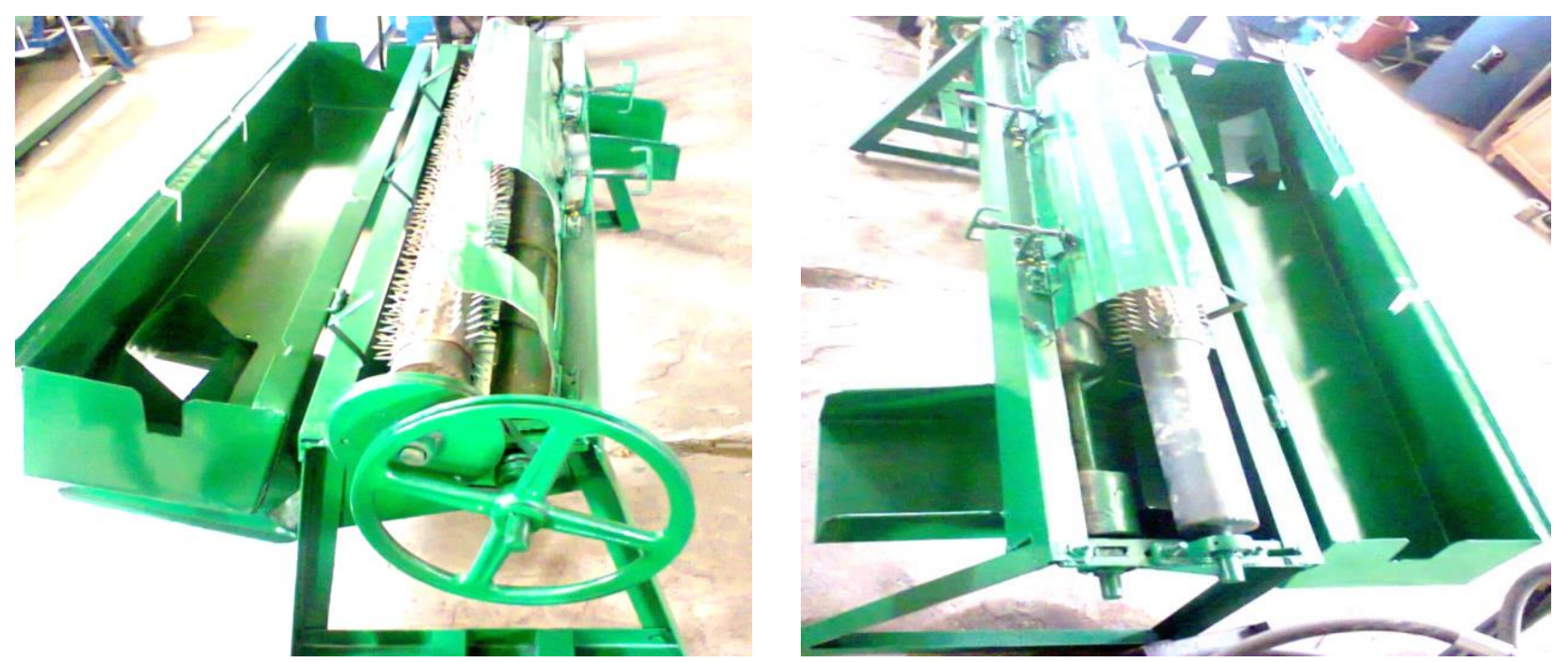

Figure 1 Picture of the internal Components of type 1 Peeler
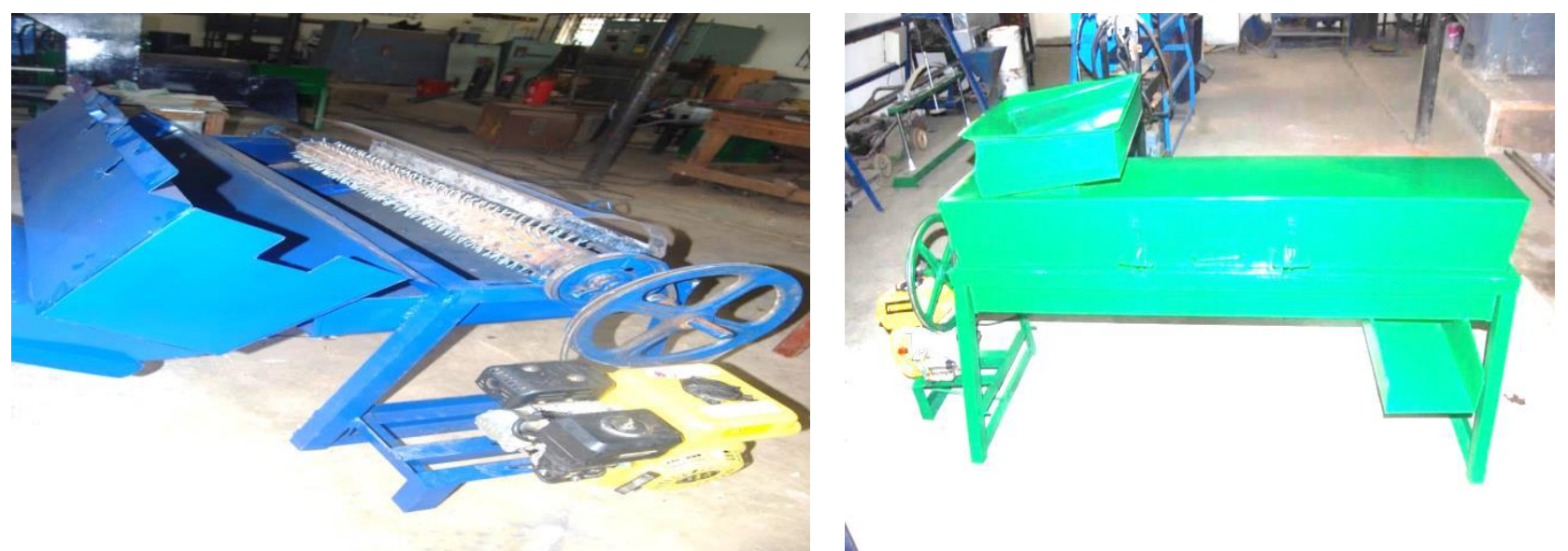

Figure 2 Picture of the side view of Type 1 Cassava Peeling Machine 


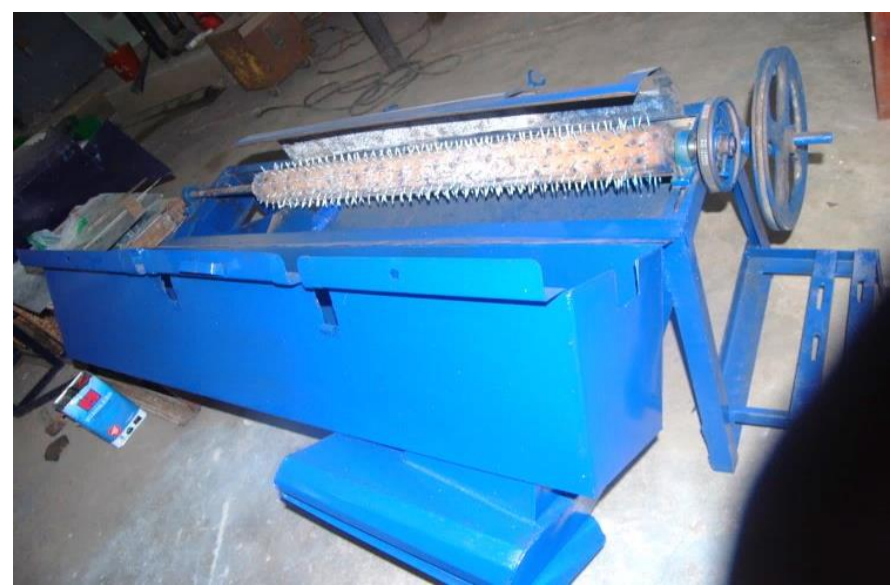

Figure 3 Internal Component of Type 2 Cassava Peeling Machine

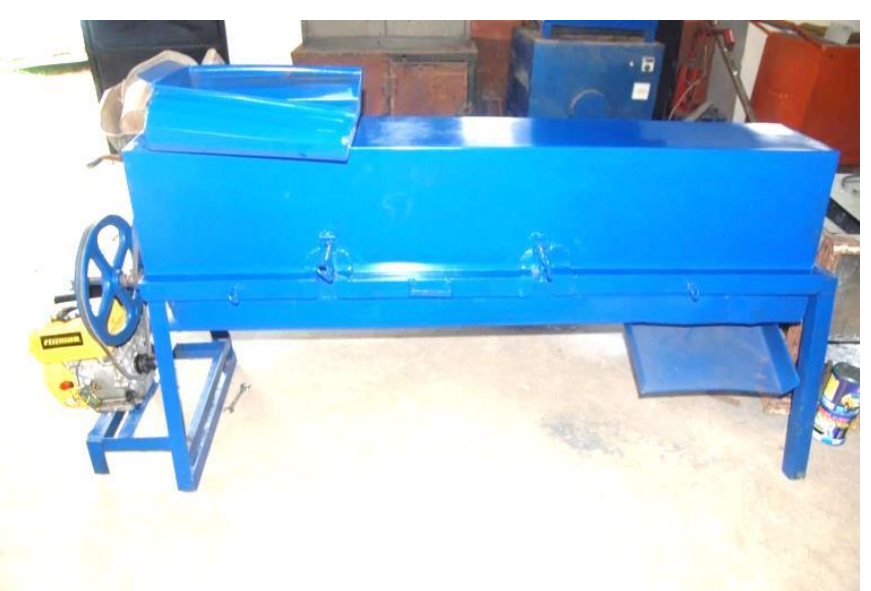

Figure 4 Picture of the Side View of Type 2 Cassava Peeler
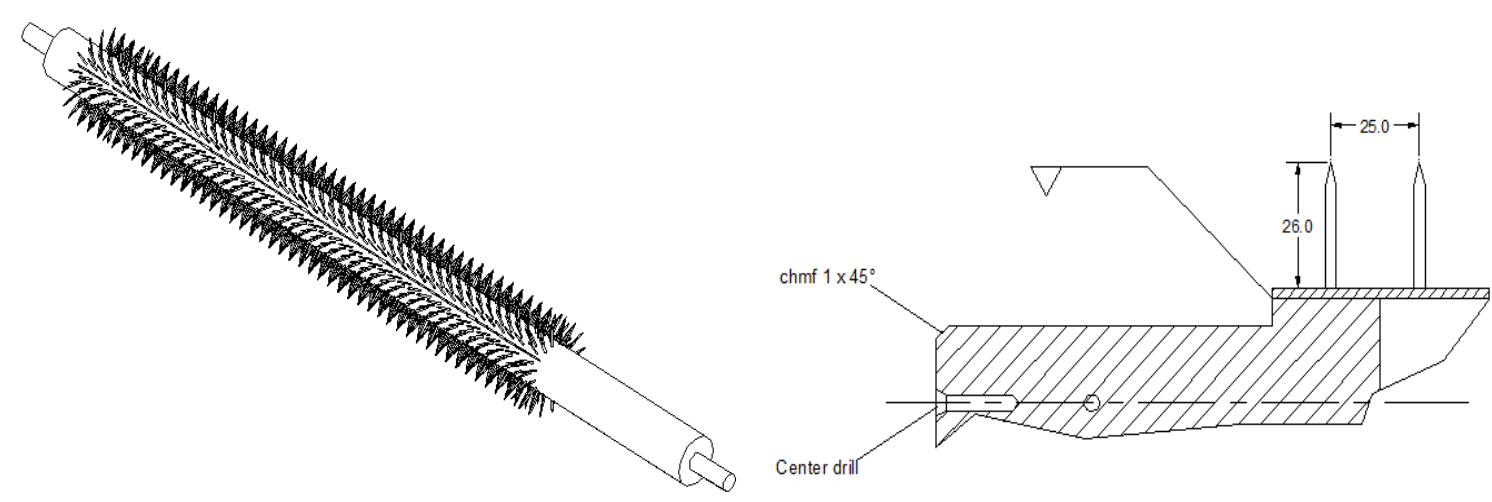

Figure 5 Peeler Shaft for Type 1 Cassava Peeling Machine (Longer spikes) 26mm
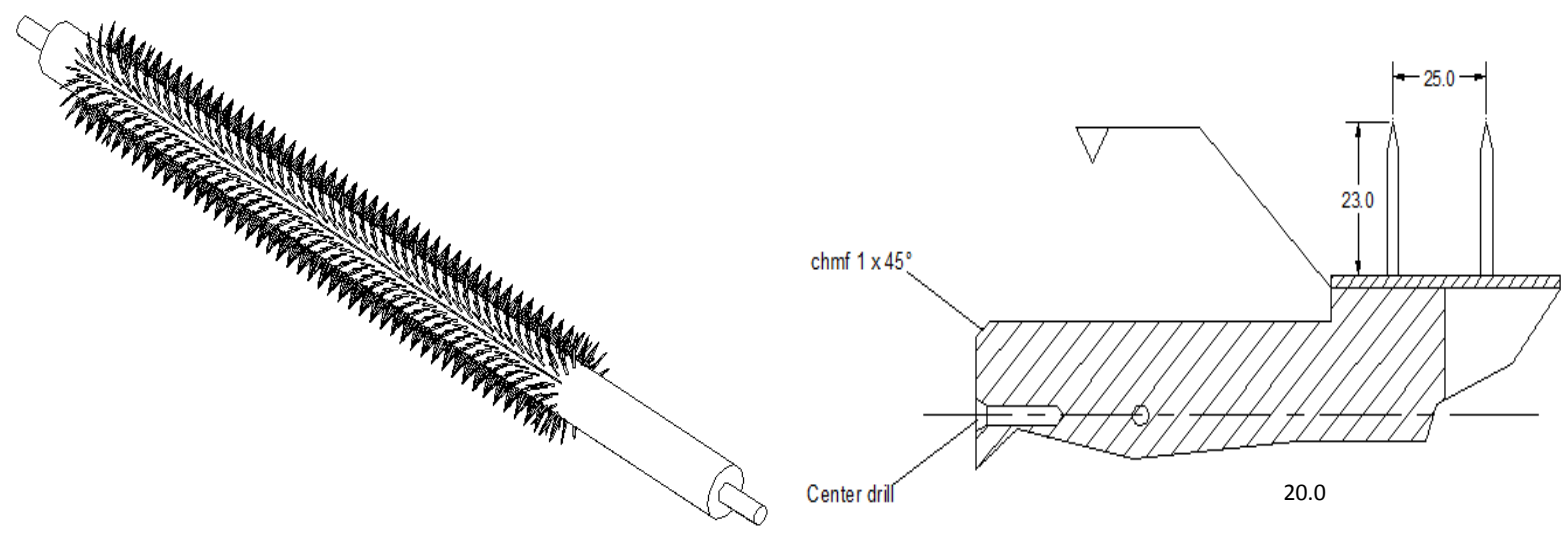

Figure 6 Peeler Shaft for Type 2 Cassava Peeling Machine (Shorter Spikes) 20mm

\subsection{Operation}

The cassava tubers as obtained from the market are grouped based on size and weight. Cassava tubers of the same weight were fed into the peeler, one at a time in a continuous process. As the screw conveyor conveys the cassava to the chute, the peeling spikes peels the cassava. The adjustable plate on the peeler pushes the cassava to the peeling spikes, where a required layer of peels is removed from the cassava. Weighing balance was used to measure weight of the materials removed.

\subsection{Theoretical Method}

The equations used in trial runs for the cassava peeling machines are as follows [23]: 


$$
\begin{aligned}
& \text { pecentage weight of cassava peels }=\frac{\text { weight of peels }}{\text { Weight of unpeeled tubers }} \times 100 \\
& \text { peeling efficiency }=\frac{\text { Weight of peel removed by Machine }}{\text { Total Weight of peels }} \times 100 \\
& \text { Percentage flesh loss of tuber }(\% F . L)=\frac{\text { weight of flesh loss removed by machine }}{\text { Total flesh weight of tubers }} \times 100 \\
& \text { Throughput efficiency }=\frac{\text { Weight of cassava fed into the machine }}{\text { time taken for cassava and its peel to completely leave the machie }} \\
& \text { Mechanical damage }=\frac{\text { sample of broken cassava }}{\text { Total number of sample cassava }} \times 100 \\
& \text { Percentage weight of peeled cassava }=\frac{\text { Weight of completely peeled cassava tuber }}{\text { Weight of unpeeled tubers }} \\
& \text { Proportion weight of cassava peels }=\frac{\text { Weight of peels }(\text { peelings })}{\text { Weight of unpeeled cassava }}
\end{aligned}
$$

\section{RESULTS AND DISCUSSIONS}

Table 1 and 2 show the results of the trial runs performed at different speeds of the peeling shaft for type 1 and type 2 machines and plotted as shown in figures $7-14$. Figure 7 shows that, the percentage weight of peeled cassava for type 1 and type 2 cassava peeling machines increases with decrease in speed of the peeling shaft, from $(71 \%, 74 \%, 80 \%$, and $85 \%)$ and $(63 \%, 68 \%, 74 \%$, and $78 \%)$ at $(110 \mathrm{rev} / \mathrm{min}, 100 \mathrm{rev} / \mathrm{min}, 90 \mathrm{rev} / \mathrm{min}$, and $80 \mathrm{rev} / \mathrm{min}$ ) respectively. Cassava peeling machine type 1 gave a better weight of peeled cassava of $85 \%$ at $80 \mathrm{rev} / \mathrm{min}$, compared to type 2 peeler that gave $78 \%$ at the same peeling speed of $80 \mathrm{rev} / \mathrm{min}$. The lowest percentage weight of peeled cassava was obtained to be $63 \%$ for type 2 compared to $71 \%$ for type 1 peeler. The difference in percentage weight of peeled cassava may be due to the differences in length of the peeling spikes. And also at low speed the peeling spikes (nails) comes into good contact with the cassava, while at high speed not all the surfaces of cassava come into contact with the peeling spikes, but brushes the surface of the cassava as the cassavas passes through the peeling spikes on the screw conveyor.

Figure 8shows the graph of percentage weight of peels against the speed of the peeling shaft. The percentage weight of cassava peels for type 1 and type 2 increases from $(13.0 \%, 13.7 \%, 14.4 \%$ and $15.0 \%)$ and $(11.5 \%$, $13.70 \%, 13.80 \%$ and $14.0 \%$ ) at the peeling speed of (110rev/min, 100rev/min, 90rev/min and 80rev/min) respectively. The percentage weight of cassava peels was recorded highest $15 \%$ at $80 \mathrm{rev} / \mathrm{min}$ for type 1 compared to $14.0 \%$ at $80 \mathrm{rev} / \mathrm{min}$ for type 2 . And the lowest percentage weight of peels was recorded $13.0 \%$ at $110 \mathrm{rev} / \mathrm{min}$ for type 1 against $11.5 \%$ at $110 \mathrm{rev} / \mathrm{min}$ for type 2 . These indicate that as the speed decreases good peeling was achieved resulting in more percentage weight of cassava peels. On the other hand when the speed increases low peeling was obtained, resulting in low percentage weight of peels

Figure 9shows the graph of percentage weight of cassava flesh loss against the speed of the peeling shaft for machine type 1 and type 2 . It can be seen from the graph that, the percentage weight of cassava flesh loss increases with an increase in speed of the peeling shaft from $(0.70 \%, 2.16 \%, 5.0 \%, 7.2 \%)$ and $(3.26 \%, 5.22 \%$, $9.14 \%, 12.40 \%)$ at $(80 \mathrm{rev} / \mathrm{min}, 90 \mathrm{rev} / \mathrm{min}, 100 \mathrm{rev} / \mathrm{min}$ and $110 \mathrm{rev} / \mathrm{min}$ ) respectively. Type 2 gave the highest percentage flesh loss as $12.40 \%$ at $110 \mathrm{rev} / \mathrm{min}$ compared to $7.2 \%$ at $110 \mathrm{r} / \mathrm{m}$ given by type 1 peeler. The lowest cassava flesh loss was obtained to be $0.70 \%$ at $80 \mathrm{rev} / \mathrm{min}$ for type 1 peeler compared to $3.26 \%$ obtained with type 2 cassava peeling machine at the same peeling speed.

Figure 10shows the graph of percentage weight of unpeeled cassava against the speed of the peeling shaft for type 1 and type 2 peelers. From the graph it can be seen that as the speed of the peeling shaft increases from $80 \mathrm{rev} / \mathrm{min}, 90 \mathrm{rev} / \mathrm{min}, 100 \mathrm{rev} / \mathrm{min}$ and $110 \mathrm{rev} / \mathrm{min}$, the percentage weight of unpeeled cassava increases from $(0.70 \%, 3.60 \%, 6.48 \%, 7.93 \%)$ and $(3.26 \%, 5.22 \%$, $9.14 \%, 12.40 \%)$ respectively. The highest percentage weight of unpeeled cassava is $12.40 \%$ at $110 \mathrm{rev} / \mathrm{min}$ with type 2 peeler and lowest of $0.70 \%$ at $80 \mathrm{rev} / \mathrm{min}$ with peeler type 1 . This may be due to the fact that as the peeling speed increases the speed of cassava in the peeling chamber increases and may pass the peeling spikes without good peeling. Good peeling was achieved at lower speeds.

Figure 11shows the graph of proportion weight of peels against the speed of the peeling shaft for machine type 1 and type 2 . From the graph it can be seen that as the speed of the peeling shaft decreases for machine type 1 and type 2 the proportional weight of cassava peels increases from $(0.68 \mathrm{~kg}, 0.74 \mathrm{~kg}, 0.78 \mathrm{~kg}, 0.8 \mathrm{~kg})$ and 
(0.63kg,0.68kg,0.74kg,0.77kg)

at

(110rev/m,100rev/min, $90 \mathrm{rev} / \mathrm{min}$, and $80 \mathrm{rev} / \mathrm{min}$ ) respectively. The proportion weight of peels was highest at $80 \mathrm{rev} / \mathrm{min}$ with a value of $0.8 \mathrm{~kg}$ and lowest of $0.68 \mathrm{~kg}$ at $110 \mathrm{rev} / \mathrm{min}$ for machine type 1 and highest at $80 \mathrm{rev} / \mathrm{min}$ with a value of $0.77 \mathrm{~kg}$ and lowest of $0.63 \mathrm{~kg}$ at $110 \mathrm{rev} / \mathrm{min}$ for machine type 2 . These indicate that, at low speed of $80 \mathrm{rev} / \mathrm{min}$, there was smooth contact of the spikes with the cassava and more peels were realized. As the speed increases to $110 \mathrm{rev} / \mathrm{min}$ there was no effective contact of the peeling tools with the cassava, resulting to low peels.

Figure 12shows the graph of peeling efficiency against the speed of the peeling shaft. The peeling efficiency increases with decrease in speed of the peeling shaft for type 1 and type 2 peelers. The efficiency increases (from $62 \%, 68 \%, 80 \%$ and $88 \%)$ and $(50 \%, 60 \%, 74 \%$, and $82 \%)$ at $(110 \mathrm{rev} / / \mathrm{min}, 100 \mathrm{rev} / \mathrm{min}, 90 \mathrm{rev} / \mathrm{min}$ and 80rev/min) respectively. The highest peeling efficiency was obtained to be $88 \%$ for type 1 at $80 \mathrm{rev} / \mathrm{min}$ and $82 \%$ for type 2 at $80 \mathrm{rev} / \mathrm{min}$. The lowest peeling efficiency was obtained to be $50 \%$ at $110 \mathrm{rev} / \mathrm{min}$ for type 2 , compared to $62 \%$ for type 1 .It can be deduced thatat low speed good peeling was achieved compared to high speed.

Figure 13shows the graph of mechanical damage against the speed of the peeling shaft. Mechanical damage is the broken pieces of cassava obtained during the peeling exercise. It is mathematically given by $\mathrm{MD}=\frac{M_{B}}{M_{P}+M_{B}}$

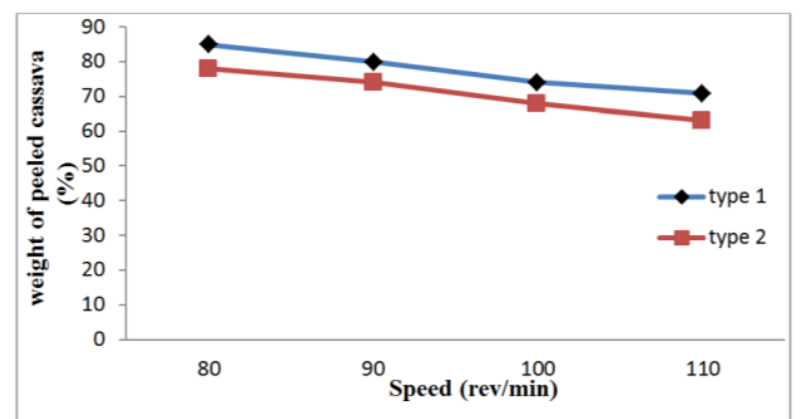

Figure 7: Graph of Weight of Peeled Cassava against the Speed of the Peeling Shaft (Type 1 and 2)

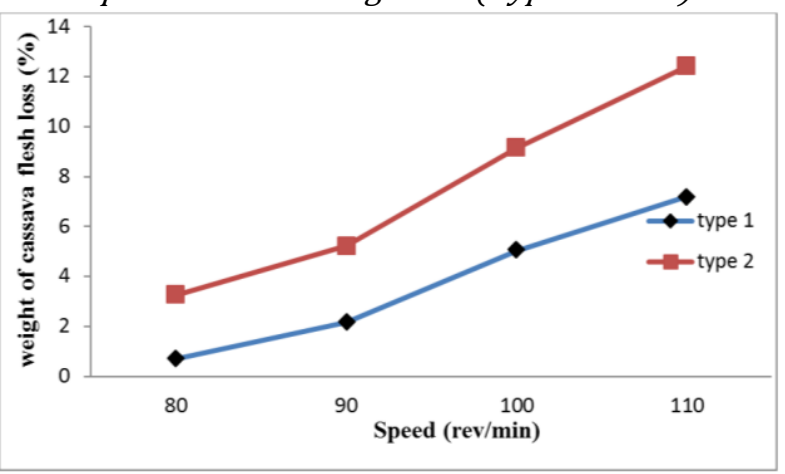

Figure 9: Graph of Weight of Cassava Flesh Loss against the Speed of the Peeling Shaft (Type 1 and 2) where $\quad M_{B}=$ mass of broken cassava and $M_{P}=$ mass of peeled cassava. As the speed of the peeling shaft increases, mechanical damage also increases for type 1 and type 2 peelers from $(0.0084 \mathrm{~kg} 0.021 \mathrm{~kg}$, $0.06 \mathrm{~kg}, 0.092 \mathrm{~kg})$ and $(0.04 \mathrm{~kg}, 0.065 \mathrm{~kg}, 0.12 \mathrm{~kg}, 0.16 \mathrm{~kg})$ at (80rev/min, 90rev/min, $100 \mathrm{rev} / \mathrm{min}$, and $110 \mathrm{rev} / \mathrm{min}$ ) respectively. Peeler type 2 gave the highest mechanical damage of $0.12 \mathrm{~kg}$ at $110 \mathrm{rev} / \mathrm{min}$ of the peeling shaft compared to $0.092 \mathrm{~kg}$ obtained when type 1 peeler was used. The lowest mechanical damage was obtained using peeler type 1 as $0.0084 \mathrm{~kg}$ compared to $0.04 \mathrm{~kg}$ obtained with type 2 peeler.

Figure 14shows the graph of throughput capacity against the speed of the peeling shaft for machine type 1 and 2 . It can be seen that throughput capacity increases with an increase in speed of the peeling shaft for both type 1 and type 2 peelers. The highest throughput capacity for machine type1 was obtained to be $1041 \mathrm{~kg} / \mathrm{h}$ at $110 \mathrm{rev} / \mathrm{min}$ and the lowest throughput capacity was obtained to be $625 \mathrm{~kg} / \mathrm{h}$ at $80 \mathrm{rev} / \mathrm{m}$ for machine type 2 . The highest throughput capacity was recorded as $1149 \mathrm{~kg} / \mathrm{h}$ at $110 \mathrm{rev} / \mathrm{min}$ and the lowest as $689.4 \mathrm{~kg} / \mathrm{h}$ at $80 \mathrm{rev} / \mathrm{min}$ for machine type 2 . This shows that at high speed of the peeling shaft the throughput capacity was high. At low speed low throughput capacity was obtained. The throughput capacity was recorded highest with type 2 peeler but the quality of the peeling in type 1 was better than in type 2 .

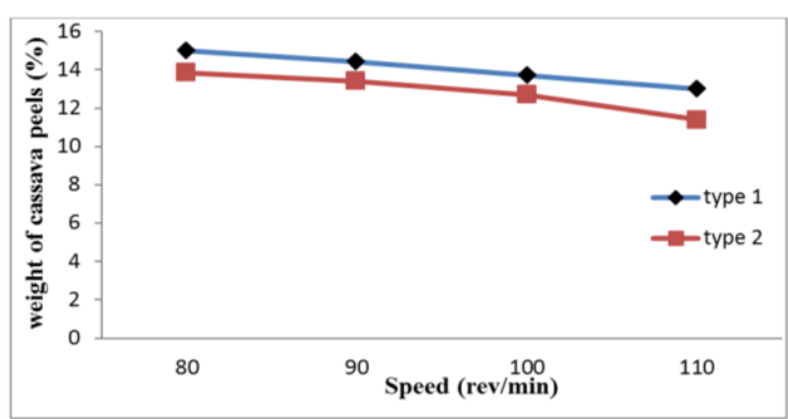

Figure 8: Graph of Weight of Cassava Peel against the

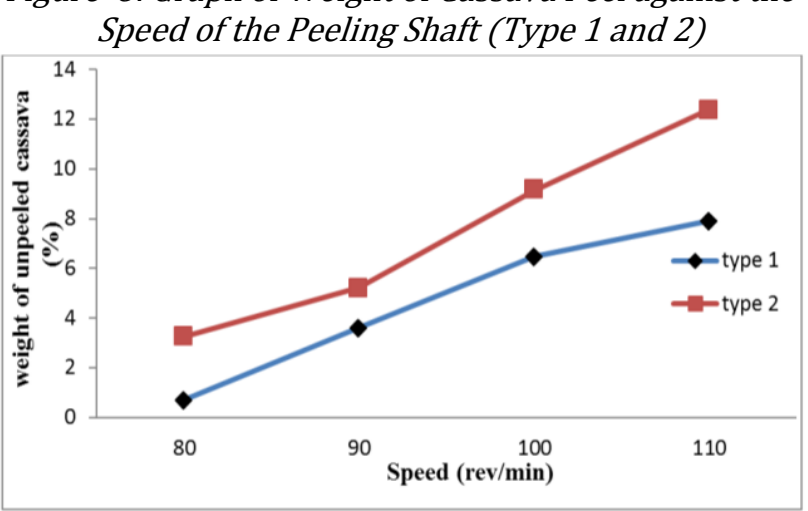

Figure 10: Graph of Weight of Unpeeled Cassava against the Speed of the Peeling Shaft (Type 1 and 2) 


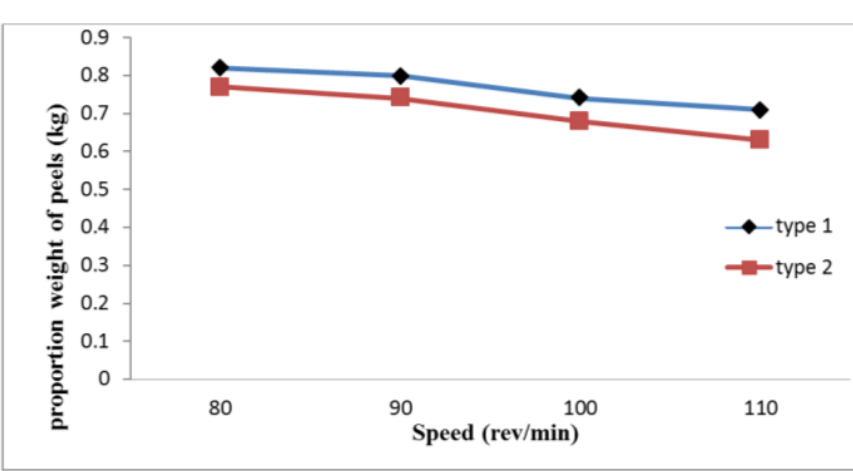

Figure 11: Graph of Proportion weight of Cassava Peels against the Speed of the Peeling Shaft (Type 1and 2)

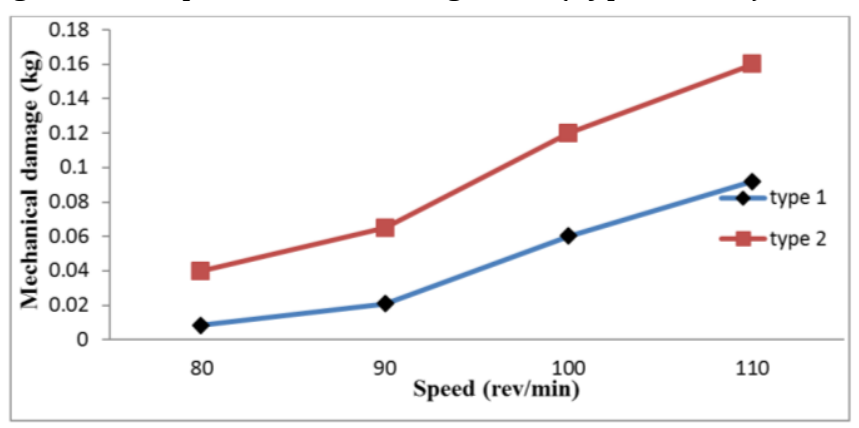

Figure 13: Graph of Mechanical Damage against the Speed of the Peeling Shaft for Machine (Type 1 and 2)

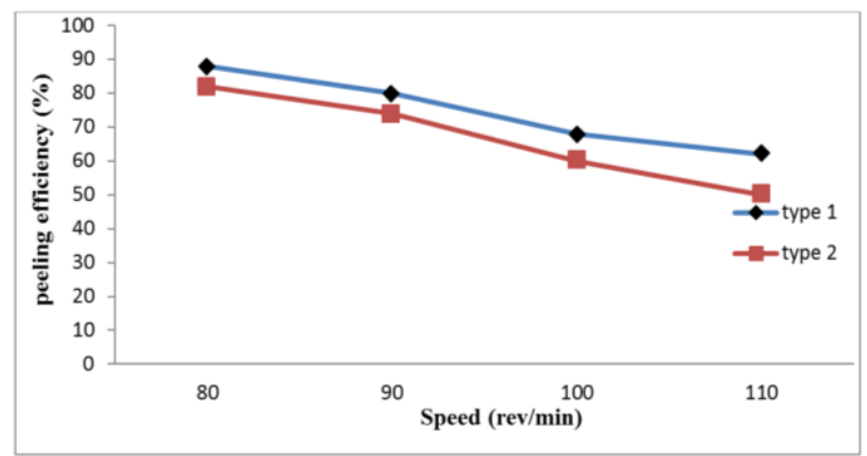

Figure 12: Graph of Peeling Efficiency against the Speed of the Peeling Shaft (Type 1and 2)



Figure 14: Graph of Throughput Capacity against the speed of the Peeling Shaft for Machine (Type 1 and 2)

Table 1: Results of the Trial runs Performed at different Speed of the Peeling Shaft (Type 1 Peeler)

\begin{tabular}{ccccccccc}
\hline $\begin{array}{l}\text { Speed } \\
(\mathrm{rev} / \mathrm{min})\end{array}$ & $\begin{array}{c}\text { Weight of } \\
\text { peeled } \\
\text { cassava (\%) }\end{array}$ & $\begin{array}{c}\text { Weight of } \\
\text { cassava } \\
\text { Peels (\%) }\end{array}$ & $\begin{array}{c}\text { Weight } \\
\text { of flesh } \\
\text { loss }(\%)\end{array}$ & $\begin{array}{c}\text { Weight of } \\
\text { unpeeled } \\
(\%)\end{array}$ & $\begin{array}{c}\text { Proportion } \\
\text { weight of } \\
\text { cassava peels } \\
(\mathrm{kg})\end{array}$ & $\begin{array}{c}\text { Peeling } \\
\text { Efficiency } \\
(\%)\end{array}$ & $\begin{array}{c}\text { Mechanica } \\
\text { ldamage } \\
(\mathrm{kg})\end{array}$ & $\begin{array}{c}\text { Throug } \\
\text { hput } \\
\text { capacit } \\
\text { y } \\
(\mathrm{kg} / \mathrm{h})\end{array}$ \\
\hline 80 & 85 & 15.0 & 0.70 & 0.70 & 0.80 & 88 & 0.0084 & 625 \\
90 & 80 & 14.4 & 2.16 & 3.60 & 0.78 & 80 & 0.0210 \\
100 & 74 & 13.7 & 5.00 & 6.48 & 0.74 & 68 & 0.0600 & 892 \\
110 & 71 & 13.0 & 7.20 & 7.93 & 0.68 & 62 & 0.0920 & 1041 \\
\hline
\end{tabular}

Table 2 Results of The Trial Runs Performed At Different Speed of The Peeling Shaft (Type 2 Peeler)

\begin{tabular}{|c|c|c|c|c|c|c|c|c|}
\hline $\begin{array}{c}\text { Speed } \\
\text { (rev/min) }\end{array}$ & $\begin{array}{c}\text { Weight of } \\
\text { peeled } \\
\text { cassava (\%) }\end{array}$ & $\begin{array}{l}\text { Weight of } \\
\text { cassava } \\
\text { peels (\%) }\end{array}$ & $\begin{array}{l}\text { Weight } \\
\text { of } \\
\text { cassava } \\
\text { flesh loss } \\
(\%)\end{array}$ & $\begin{array}{c}\text { Weight of } \\
\text { unpeeled } \\
\text { cassava (\%) }\end{array}$ & $\begin{array}{c}\text { Proportion } \\
\text { weight of } \\
\text { cassava peels } \\
(\mathrm{kg})\end{array}$ & $\begin{array}{l}\text { Peeling } \\
\text { Efficiency } \\
(\%)\end{array}$ & $\begin{array}{c}\text { Mechanica } \\
\text { l damage } \\
(\mathrm{kg})\end{array}$ & $\begin{array}{c}\text { Throughpu } \\
\text { t capacity } \\
(\mathrm{kg} / \mathrm{h})\end{array}$ \\
\hline 80 & 78 & 14.00 & 3.26 & 3.26 & 0.77 & 82 & 0.040 & 689 \\
\hline 90 & 74 & 13.80 & 5.22 & 5.22 & 0.74 & 74 & 0.065 & 862 \\
\hline 100 & 68 & 13.70 & 9.14 & 9.14 & 0.68 & 60 & 0.120 & 985 \\
\hline 110 & 63 & 11.50 & 12.40 & 12.40 & 0.63 & 50 & 0.160 & 1149 \\
\hline
\end{tabular}

\section{CONCLUSION AND RECOMMENDATIONS}

\subsection{Conclusion}

Developing a cassava peeling machine with a longer peeling spikes (nails) $26 \mathrm{~mm}$ gave better values of percentage weight of peeled cassava, percentage weight of cassava peels, percentage weight of cassava flesh loss, percentage weight of unpeeled cassava, peeling efficiency, proportion weight of cassava peels and mechanical damage compared to the values obtained by the cassava peeling machine developed with the shorter peeling spikes (nails) $20 \mathrm{~mm}$.

\subsection{Recommendations}

1. Further study should be carried out on longer nails to determine the optimum peeling efficiency of nails.

2. Future work should incorporate electronic automation system to enhance efficiency

3. More energy saving machines should be examined for future development 


\section{REFERENCES}

[1] ARS. Accessed 15 January, 2015, from www.ars.grin.gov/bin 2010.

[2] Oriole, K. O., and Raji, A. O "Trends at Mechanizing Cassava Post-Harvest Processing Operations" International Journal of Engineering and Technology; Vol. 3, No. 9,Pp879-887. 2013.

[3] APS. Accessed 15 January, 2015 from www.apsnet.org 2015.

[4] FAO Accessed 15 January, 2015, from www.fao.org 2015.

[5] Uthman, F. "Design and Fabrication of Cassava Lump Breaking and Sieving Machine" Oasis Journal of Research and Development, Vol. 1, No. 2, p42-50. 2011,

[6] Erhabor, P. O and Emokaro, C. O "Economic Importance of Cassava” In: Erhabor, P. O. Azaiki, S.S and Ingawa, S. A (eds) Cassava the White Gold, initiative Publication Co. Benin. Pp1-16, 2007.

[7] Linley C. K., Chrissie, K., James, N., Felistus, C., Jonathan, M., Sidney, S., Janice, J "Bitter Cassava and Women an Intriguing Response to Food Security" LEISA Magazine, 18, 4, www.agriculturesnetwork.org 2002.

[8] FAO (2011). Accessed 15 January, from www.fao.org 2015.

[9] Igbeka, J. C “Mechanization of Cassava Tuber Peeling” Prac. Int. Symp. Mechanization, Harvesting and Subsequent Processing of Agricultural Products in Tropical Africa and the Manufacturing of Relevant Agricultural Implements 11-15 February, Pp12, 1985.

[10] Igbeka, J. C “Relationship of Moisture Diffusivity with Moisture Content and Temperature in Cassava (manihotesculenta) and Potato (solarium tuberous) during Drying" Nigerian Journal of Science: 14: Pp19321. 1980.

[11] Adetunji, O. R and Quadri, A. H "Design and Fabrication of an Improved Cassava Grater" Pracific Journal of Science and Technology, Vol. 12. No 2, Pp120-129. 2011.

[12] Adetan, A. D., Adekoya, I. O., Aluko, O. I. and Makanjuola, G. A. "An Experimental Mechanical Cassava Tuber Peeling Machine" Journal of Engineering. 59: Pp349-353. 2005.

[13] Ademosun, C. O., Jimoh, O. M., and Olukunle, J. O "Effect of Physical and Mechanical Properties of
Cassava Tubers on the Performance of an Automated Peeling Machine" Nigerian Journal of Engineering and Applied Sciences Vol.5, No.4, Pp47-60. 2012,

[14] Aghetoye, A. S “Improving the Technology of Cassava Harvesting and Processing Mechanization for Food Security in Nigeria" A Paper Presented at the International Conference on Science and Technology, held at the Federal University of Technology, Akure, Ondo State, Nigeria. August 14-19, Pp196-204. 2005.

[15] Adetan, A. D. Adekoya, O. L and Aluko, B. O "Theory of Mechanical Method of Peeling Cassava Tubers with Knives" International Journal of Research and Development Vol.2, No.3, Pp54-69. 2006,

[16] Ezekwe, G. O "A Future for Achieving a Constant Depth of Peel in the Mechanical Peeling of Cassava" Nigerian Journal of Engineering Vol.1, No. 3, Pp174181. 1976.

[17] Ezekwe, G. O "Mechanizing Cassava Peeling" the Project Development Agency (PRODA) Cassava Nibbling Machine. PRODA Technical reports, No.1 Pp. 1-20, Sept, 1979.

[18] Odigboh, E. U. "A Cassava Peeling Machine Development, Design and Construction" Journal of Agricultural Engineering Research, 21, Pp361-369. 1976.

[19] Nwokedi, P. M "Performance Evaluation of Cassava Peeling Machine" In: Tropical Root Crops. Production and Uses in Africa, E. R. Terry, E. U. Doku, O. B Arene and N. M. Machungu (eds.) Int. Development Research Centre, Pp108-110.

[20] Davies R. M., Olotunji, M. O and Bunbai, W. O “Design and Development of a Pedal Powered Cassava Peeling Machine" International Journal of Research and Development, Vol. 4, No. 3, Pp341-345. 2008.

[21] Abdulkadir, B. H "Design and Fabrication of a Cassava Peeling Machine" Journal of Engineering (IOSRJEN). Vol. 2, No. 6, Pp1- 8. 2012.

[22] Olukunle, O. J. and Jimoh, M. O "Comparative Analysis and Performance Evaluation of three cassava Peeling Machines" International Research Journal of Engineering Science, Technology and Innovation (IRJESTI) Vol. 1, No. 4, Pp94-102. 2012,

[23] Oluwole, 0. 0. and Adio, M. O. "Design and Construction of a Batch Cassava Peeling Machine" Journal of Mechanical Engineering and Automation Vol. 3, No.1, Pp16-21. 2013, 